\title{
A cluster of inflammatory breast cancer (IBC) in an office setting: Additional evidence of the importance of environmental factors in IBC etiology
}

\author{
TINA J. DUKE ${ }^{1}$, NASREEN C. JAHED ${ }^{2}$, CARMELA C. VENEROSO $^{2}$, RICARDO DA ROZA $^{3}$, OWEN JOHNSON $^{4}$, \\ DANIEL HOFFMAN ${ }^{2}$, SANFORD H. BARSKY ${ }^{5}$ and PAUL H. LEVINE ${ }^{2}$ \\ ${ }^{1}$ Office of Water, U.S. Environmental Protection Agency, 1200 Pennsylvania Ave NW Washington, DC 20460; \\ ${ }^{2}$ Department of Epidemiology and Biostatistics, The George Washington University School of Public Health and \\ Health Services; ${ }^{3}$ Eden Valley Medical Center; ${ }^{4}$ The Inflammatory Breast Cancer Foundation; ${ }^{5}$ Department \\ of Pathology, Ohio State University Comprehensive Cancer Center, Columbus, OH 43210, USA
}

Received May 12, 2010; Accepted July 5, 2010

DOI: $10.3892 /$ or_00000983

\begin{abstract}
We investigated a cluster of three cases of inflammatory breast cancer (IBC) diagnosed within 10 months in an office setting of 24 people. Information about medical history, pregnancy history, family history of breast cancer, oral contraceptive use/hormone replacement therapy, exposure to possible oncogenic agents and tumor promoters were obtained to determine whether there were differences in risk factors for IBC between cases and controls. The physical environment and location of the cases' office raised concern about air and water quality as well as radiation as being contributory risk factors for developing IBC. Of the three women with IBC, two had high exposures to pesticides/herbicides, all three used oral contraceptives and two used hormone replacement therapy at the time of diagnosis, two had a family history of breast cancer, and two were obese. Among fifteen controls four had pesticide/herbicide exposure, one had a family history of breast cancer, nine used oral contraceptives, seven used hormone replacement therapy, and five were obese. No specific environmental causes were established for this cluster. Several promoting factors have been suggested that could result in subclinical breast cancer emerging as IBC. Among them are exogenous hormones and exposure to herbicides/pesticides.
\end{abstract}

\section{Introduction}

Inflammatory breast cancer (IBC), a highly aggressive form of breast cancer, is considered to be relatively rare (less than $4 \%$ of all breast cancers in the US) (1-4). Several studies

Correspondence to: Dr Paul H. Levine, The George Washington University School of Public Health and Health Services, 2100-W Pennsylvania Ave NW, Suite 817 Washington, DC 20037, USA E-mail:sphphl@gwumc.edu

Key words: inflammatory breast cancer, environmental factors, oral contraceptives, hormone replacement therapy indicate that environmental factors may play an important role in aggressive breast cancer (5-7). These studies document the observation that the risk factors for aggressive breast cancer, including IBC, are not the same as those for developing breast cancer. For example one study found that organochlorines do not increase incidence, but promote tumor aggressiveness (7) and early age (20 or younger) at first pregnancy, a deterrent to developing breast cancer (8), is associated with both aggressive disease as measured by tumor grade (9) and the clinical manifestation of IBC (6).

\section{Materials and methods}

Study population. The three cases of IBC were diagnosed within a 10-month period between May 1999 and March 2000 in an office of 24 long-term employees (23 females and 1 male) in Castro Valley, California. All three of these cases worked in a space on one side of the office with well documented environmental health concerns.

The male and five of the females chose not to participate in the study. The three cases and 15 controls were interviewed to determine if specific risk factors for IBC could be identified. The three cases moved into the second floor of the office building in 1985, and they were the first to work in the space.

Environmental studies. Environmental surveys were conducted for hazards in the office building as required by the California Health Department (CHD). The office being studied was located above a mammography and MRI imaging center. Five measurements of air quality, a water sampling study, three MRI surveys and evaluation of radiation leakage between the mammography unit and the office were each performed by contractors between February 1988 and April 2000. These environmental studies evaluate the office in its entirety. All three cases had office spaces located on the side of the office that had the worst air circulation according to the employees and indoor air quality studies.

Interviews and questionnaires. The three cases were interviewed in person by a researcher and detailed information on 
history of any present illnesses, home and occupational exposures, pregnancy history, and family history were obtained. Subsequently, a trained interviewer conducted a telephone interview of the two surviving cases and 15 controls using a structured questionnaire developed for obtaining demographic information about IBC risk factors. One of the three cases died before the follow-up interview.

All study participants were asked about their menstrual history, pregnancy history, exogenous hormone use, family history of breast cancer, surgical removal of their ovaries, medical history, exposures to possible cancer-causing pollutants in the environment such as herbicides and pesticides, and details of the participant's breast cancer diagnosis (cases only). Exogenous hormone use included information on the use of oral contraceptives (OC), hormone replacement therapy, and hormones taken to help become pregnant or to maintain a pregnancy. Information was obtained on the estimated number of years that the case used the hormone. Pregnancy history included number of live births and the age when the case gave birth to her first child. Women who reported a first-degree relative (mother, daughter or sister) had been diagnosed with breast cancer or women who reported a second degree relative (grandmother, aunt, first cousin) had been diagnosed with breast cancer at a young age (less than 35 ) or diagnosed with breast and ovarian cancer were considered to have a family history of breast cancer. A woman was considered to have been pre-menopausal if her menstrual periods had not ended before her date of diagnosis and post-menopausal if her menstrual periods ended before her date of diagnosis due to either natural menopause or surgical removal of her ovaries. The cases' average weight was considered their weight as an adult before the date of diagnosis. The diagnosis of IBC was confirmed by biopsy from the physician of the 3 cases, who provided the pathology reports.

Laboratory studies. Tissue samples from the three cases of IBC were reviewed by standard light microscopy. Paraffin embedded sections $(5 \mu \mathrm{m})$ were stained with hematoxylin and eosin and reviewed pathologically by the same research pathologist. Details about the pathology of the cases are provided later in this document. After lymphovascular tumor emboli were documented, additional sections were studied immunocytochemically with specific antibodies, which have been shown in recent studies to further define the inflammatory carcinoma phenotype (10-13).

The antibodies used for the immunocytochemistry included monoclonal antibodies to E-cadherin (clone HECD-1) at a concentration of 1-10 $\mu \mathrm{g} / \mathrm{ml}$ (Zymed Laboratories, San Francisco, CA); MUC-1, (clone HMPV, mouse IgG1) (PharMingen), at a concentration of $1-100 \mu \mathrm{g} / \mathrm{ml}$; sialyl-Lewis $\mathrm{X}$ (sLeX) (clone CSLEX-1) and sialyl-Lewis A (sLeA) (clone CCOL-2) (UCLA Tissue Typing Laboratory, Los Angeles, CA) each at concentrations of $10 \mu \mathrm{g} / \mathrm{ml}$; and control mouse IgG1 (Dako, Denmark) at a concentration of $50 \mu \mathrm{g} / \mathrm{ml}$. NonIBC and normal breast tissues were used as controls.

\section{Case report}

Case 1, D.R. This 53 year old Caucasian woman had her breast cancer diagnosed during a routine mammogram on
May 15, 1999. She routinely had been getting mammograms but missed a year because her mother was ill. Between January of 1997 and May of 1999 she had developed a focal area of density with clustered microcalcifications and architectural distortion in the upper aspect of the right breast. She had a normal clinical breast examination in April 1999 and there were no obvious clinical symptoms of IBC prior to early May when she noticed a small area of redness approximately $3 \times 3 \mathrm{~cm}$, which was still there the following day. Her only additional symptom was a stabbing pain in her breast that did not subside until chemotherapy was initiated.

In one week, her breast had changed dramatically and was more red and firm. A lump could be felt on the right side but the redness was more medially located around the nipple. At no time did the redness involve more than half of the breast. She saw her surgeon who noted mid periareolar swelling and a small area of erythema and an orange-peel look to the skin (peau d'orange). The surgeon also noted a suspicious enlarged lymph node in the right axilliary tail. His initial diagnosis at that time was IBC, although her physical findings never involved more than half of her breast. A breast biopsy on June 2, 1999 showed a moderately differentiated invasive ductal carcinoma with a comedo pattern. Of the 15 sections of skin, one contained two definite foci of dermal lymphatic invasion. The tumor was ER $(80 \%)$ and PR $(20 \%)$ positive and Her2-neu negative.

She received neoadjuvant chemotherapy (four cycles of adriamycin ${ }^{\circledR}$ and cyclophosphamide ${ }^{\circledR}$ ) from June to August 1999 with a good response. Radiation therapy was given in September and October of that year followed by seven cycles of cyclophosphamide ${ }^{\circledR}$, methotrexate ${ }^{\circledR}$ and 5-fluorouracil ${ }^{\circledR}$ which ended in January 2000. In March 2000 she had a right modified radical mastectomy plus a prophylactic left mastectomy. No residual carcinoma was seen and there was no evidence of tumor in the 12 lymph nodes removed. Three cycles of Taxol ${ }^{\circledR}$ were given post operatively; a fourth course was not given because of peripheral neuropathy. She has remained free of disease since September 2000. (Last followup: March 17, 2006).

Environmental data. She had taken oral contraceptives for an eight year period but did not take hormone replacement therapy because her sister had developed breast cancer. She had been exposed to pesticides and herbicides as a result of home use of these substances for 28 years.

Family history. She had a strong family history of breast cancer; her mother died of breast cancer in her early 30's and her sister died at 29 years old with breast cancer. Her maternal and paternal grandmothers both had breast cancer, the former at a young age.

Case 2, P.J. This 46-year old Caucasian female had her routine mammogram in February, 1999 that was interpreted as being normal with some calcifications. She was told to monitor them for 6 months but she was concerned about the calcification and saw her surgeon, the same surgeon who had seen Case 1. He advised her to repeat the mammogram in three months. At her follow up mammogram May, 1999 there were 'little changes'.

She had a right breast biopsy June 24, 1999 using wire localization technique. A follow-up mammography confirmed 
that the lesion had been removed. The pathology report was interpreted as showing benign, proliferative, fibrocystic changes of the breast with calcification. No neoplastic component was noted. On a follow-up visit she had mild breast soreness and skin changes which were interpreted as dermatitis from the Tegaderm $^{\circledR}$, which was the dressing used following her biopsy.

One week later, she felt that her breast was 'hard as a rock' but she attributed that to the biopsy. When she returned to the surgeon July 21, 1999, reporting additional swelling with a pressure sensation in the right breast, he noted visible swelling with mild to moderate erythema, especially inferiorly. He performed a direct aspiration near the incision to determine if there was a hematoma, but no blood was aspirated.

The doctor's clinical impression was that the patient was experiencing 'diffuse soft-tissue infection cellulitis resulting from the biopsy and wire technique'. An ultrasound on July 29, 1999 was interpreted as showing an irregular, amorphous density in the outer aspect suggesting local inflammation but no definite abscess and she was started on $500 \mathrm{mg}$ Duricef ${ }^{\circledR}$ po bid for two weeks. She did not respond and the dosage was increased to $1 \mathrm{gm}$ bid and Rifampicin ${ }^{\circledR}$ was added. An ultrasound in late July showed no evidence of abscess. When seen again by the surgeon August 12, 1999, she reported improvement in her symptoms and was only taking Duricef. On August 23, 1999 her breast was warm and red and in September 1999 she saw an oncologist, who noted 'an orange peel look' (peau d'orange), firmness of the entire right breast, no tenderness, mild and diffuse erythema and enlarged right axillary lymph nodes. Another ultrasound ruled out an abscess and her surgeon asked the oncologist for a second opinion, which led to a fine needle aspiration which was not diagnostic, but revealed some atypical cells. Both doctors agreed on the need for a biopsy and two new lumps were now noted for the first time near the right axillary area. An open excisional biopsy showed carcinoma and both dermal lymphatic and perineural invasion were interpreted as IBC. The biopsy of an axillary lump was interpreted as showing metastatic carcinoma. The tumor was $\mathrm{ER}^{+}(80 \%), \mathrm{PR}^{+}(50 \%)$ and Her2-neu ${ }^{-}$.

A whole body scan on September 23, 1999 was consistent with metastatic disease in the skull, right scapula, posterior ribs, multiple vertebrae, right sternoclavicular joint, posterior iliac crests bilaterally, and right acetabulum. Chemotherapy was initiated with Adriamycin ${ }^{\circledR}$ and Cytoxan ${ }^{\circledR}$. After seven cycles between October 1999 and January 2000 she responded well. She was then given radiation therapy in February 2000 along with concomitant chemotherapy, methotrexate ${ }^{\circledR}$ and 5-fluorouracil ${ }^{\circledR}$ which was discontinued in April 2000. She was treated with tamoxifen ${ }^{\circledR}$ and appeared to be in remission until February 2001 when she developed skin nodules in her chest. Biopsy confirmed the presence of metastatic disease and she was started on weekly Taxol ${ }^{\circledR}$. Persistent thrombocytopenia led to a bone marrow biopsy which confirmed bone marrow involvement with the tumor. Taxotere ${ }^{\circledR}$ and Arimidex ${ }^{\circledR}$ led to significant clinical improvement until August 2001 when she developed a malignant pleural effusion. Gemzar ${ }^{\circledR}$ was unsuccessful and she died in late 2001.

Environmental data. She reported taking oral contraceptives (Orthonovum ${ }^{\circledR}$ ) intermittently since she was married in 1976 , but discontinued them because of problems with hypertension. She had taken no oral contraceptives since 1997. Between
April and September 1999 she took Prempro ${ }^{\circledR}$ for mood swings and hot flashes; she was perimenopausal at the time. She took one pill per day as prescribed by her physician. She was taking this HRT until the time of her diagnosis.

Family history. She had a strong family history of breast cancer. She had two paternal aunts with both breast cancer and ovarian cancer. The daughter of one of these aunts developed breast cancer in her 30's. Prior to being prescribed Prempro $^{\circledR}$, she was asked if she had a family history of breast cancer. She originally said no, because she did not believe breast cancer on the paternal side was important.

Case 3, C.J. This 54 year old Caucasian woman's symptoms began with 'nerve pains' in early 2000 which coincided with her menstrual cycle. She had seen her primary physician December 15, 1999 and everything appeared normal. She noted an inverted nipple and enlargement of her left breast followed by a green discharge in February 2000. She thought she had mastitis and saw her gynecologist to request a mammogram and he conducted a breast exam at that time. The left mammogram obtained February 23, 2000 showed 'an area of ill-defined density in the upper outer quadrant of the left breast showing microcalcifications and adjacent skin thickening' which had not been present in the previous study of January 1999. After the mammogram, her breast began to feel warm but she could not feel a discrete lump. On March 1, 2000 she saw her surgeon, who had also seen Case 1 and Case 2, and his initial diagnosis was IBC. A chest X-ray the same day was unremarkable. She then developed redness of the breast and within two weeks the entire breast was red.

A left breast and skin biopsy were obtained March 3, 2000 that revealed moderately differentiated infiltrating ductal carcinoma. Adenocarcinoma was present in the dermal lymphatics and the skin also showed vascular invasion. Her cells were $60 \% \mathrm{ER}^{+}$and $5 \% \mathrm{PR}^{+}$. She was first treated with neoadjuvant chemotherapy between February and August 2000; four cycles of Adriamycin ${ }^{\circledR}$ and Cytoxan ${ }^{\circledR}$ (cyclophosphamide) followed by four cycles of Taxol $^{\circledR}$. She had a complete clinical response. This was followed by radiation therapy and 20 mg tamoxifen ${ }^{\circledR} 20$ p.o daily. In January 2001 she had a mastectomy and remained in remission until January 2002 when she was discovered to have enlarged cervical lymph nodes. A fine needle aspirate biopsy confirmed the presence of metastatic carcinoma and she was treated with Taxotere ${ }^{\circledR}$ until April 2002, when she developed shortness of breath due to a malignant pleural effusion. Her chemotherapy was switched to Gemzar ${ }^{\circledR}$ and she was placed on an aromatase inhibitor, Femara ${ }^{\circledR}$. The treatment was not effective and she died in May of 2002.

Environmental data. She was raised in a house near railroad tracks and she lived with her mother (an avid gardener), until she was 23 years old. Every summer insecticide bombs were used to kill insects and spiders. Sprays were applied every three months to attack ants. She was also an avid gardener who applied herbicides/pesticides twice per year for her adult life. She took oral contraceptives for 11 years until she had a hysterectomy for metrorrhagia. Subsequently she took Premarin ${ }^{\circledR}$ from 1979 to 2001, a 22 year exposure to exogenous hormones. The HRT was taken until the time of her diagnosis. 


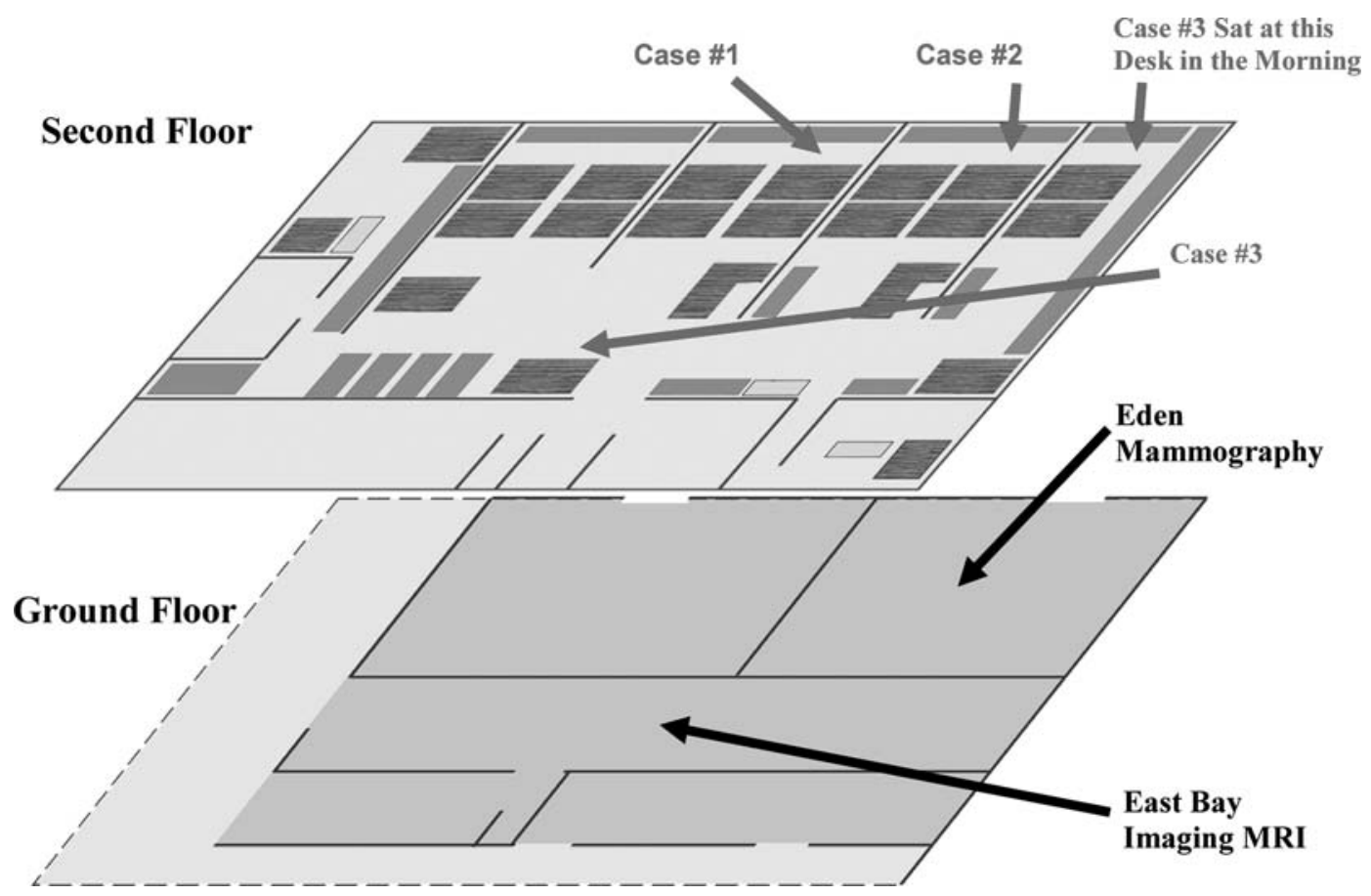

Figure 1. Castro valley office building.

Family history. Her mother was adopted and there was no family history of breast cancer in any known family members.

Office setting. The 18 women who participated in the study worked on the second floor of a California office building (Fig. 1). All cases and controls were long-term clerical employees. The average length of employment for the cases was 14 years and one month and 14 years 9 months for the controls.

From 1986 to 1999 there had been numerous cases of illness involving upper respiratory problems as well as eye, nose and throat irritation, headaches, fatigue and lethargy, skin irritation and rashes. The workers reported concerns about ventilation in their office. According to air quality studies performed between 1989 and 2000, the vents in the ceiling were not supplying air to one side of the office floor; this was the side which housed the office spaces that the cases occupied. The ventilation system was turned off at night.

The office contained stored billing records printed on carbonless copy paper (CCP). The CCP billing records were stored on shelving at a temperature above 68 degrees Fahrenheit in the same area where the cases and controls worked. File boxes were stacked in front of windows that did not open in an area where ventilation did not operate adequately when in use.

A magnetic resonance imaging (MRI) center and mammography center were both located on the first floor of the office building (Fig. 1). The imaging center had occupied the building for 10 years and the mammography center for seven years. There was no shielding between the mammography and MRI center on the first floor and the workspace on the second floor. In January 1999 the mammography center replaced their existing mammography machine with a new one and in September 1999 the imaging center closed its business.
The office staff worked on a flexi-time schedule, and the three cases were among the first employees to arrive at work each day between 5:30 a.m. and 6:30 a.m. Two of the three cases had workspaces above the mammography center (Fig. 1). Their workspaces were also on the side of the second floor where air quality studies performed between 1989 and 2000 determined insufficient air supply distribution. The third case had an assigned desk directly above the MRI center, but in the morning she would sit at a desk near the other cases above the mammography center to socialize with coworkers.

Environmental surveys. As mentioned earlier, the employees expressed considerable concern about their working environment and potential exposures. The California Health Department (CHD) required the employer to conduct a survey of the environment for radiation and other environmental hazards in the office building. Contractors conducted surveys and assessments between January 1989 and April 2000. A summary of their findings is presented in the paragraphs below.

In March of 1999 surveys of the static magnetic field from the MRI on the second floor of the building were below the lowest health guideline of 5.0 Gauss. These surveys were conducted after the installation of new equipment. A 1999 radiation leakage survey was performed and the report stated that no radiation could be detected on the second floor, despite the absence of concrete between the two floors. As with the MRI equipment, however, the old mammography equipment had been replaced and the survey was conducted with new equipment present. Only one water sampling study was performed and the results indicated that the only organic compounds detected were present at allowable California maximum contaminant levels and were lower than typical levels supplied by East Bay Municipal Utility District. 
A

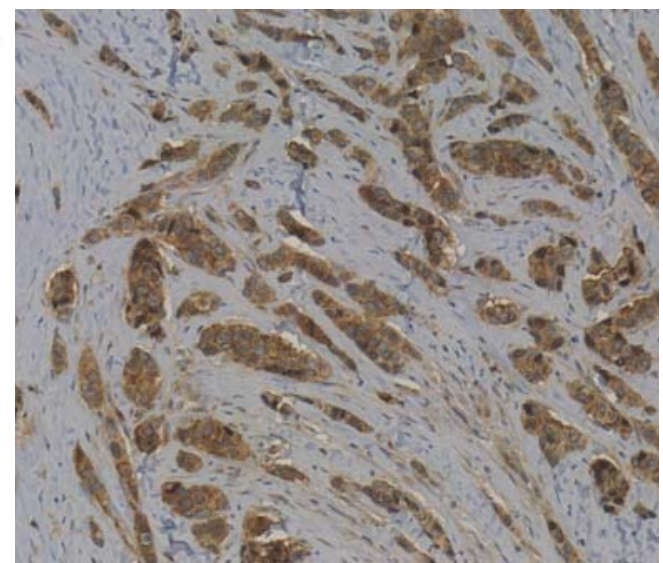

$\mathrm{B}$

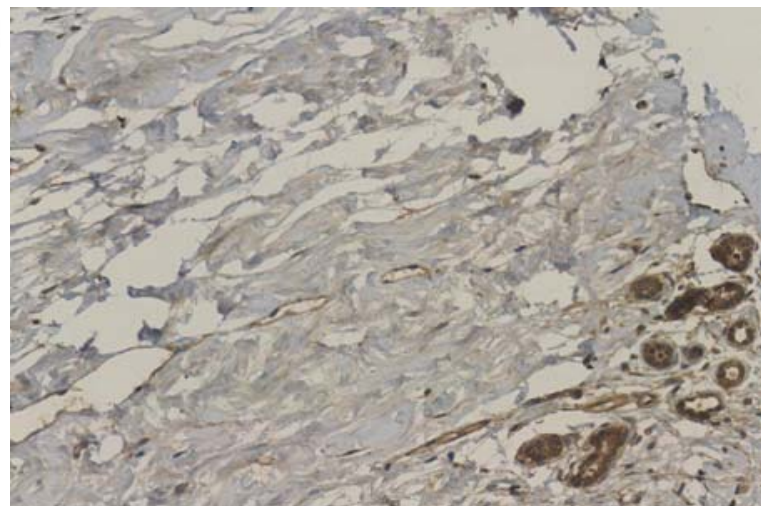

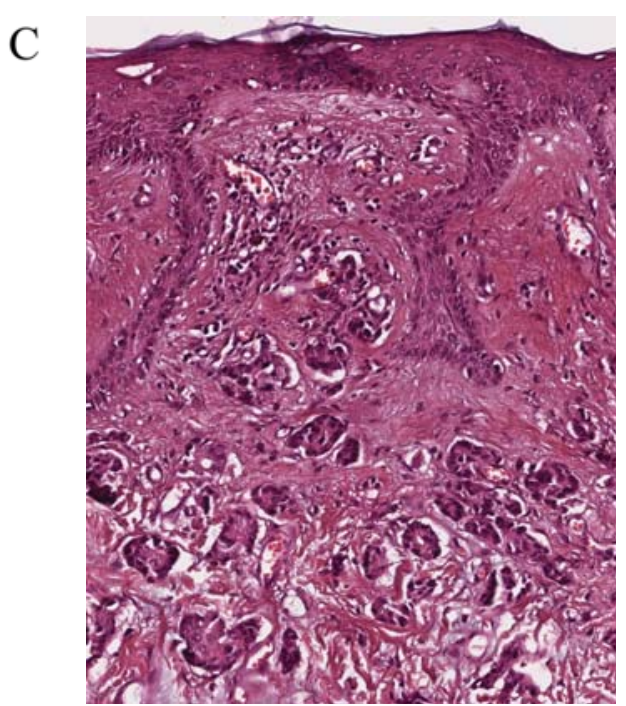

Figure 2. Lymphovascular emboli. (A) Lymphovascular emboli display intense E-cadherin plasma membrane immunoreactivity. Similar observations were made with MUC-1 immunoreactivity. (B) Lymphovascular emboli display absent sialyl-Lewis A immunoreactivity (left) compared to strong sialyl-Lewis A immunoreactivity (right) exhibited by normal acini. Similar results were observed for sialyl-Lewis X. (C) Lymphovascular emboli are observed within dermal lymphatics. Note the clear space which exists around the compact tumor embolus indicative of its retraction away from the vessel wall.

There were five air quality studies performed. The first air study in 1989 indicated that the levels of $\mathrm{CO}_{2}$ and $\mathrm{CO}$ were above the levels indicated by the American Society of Heating, Refrigerating, and Air Conditioning Engineers (ASHRAE) (14). Additional studies showed an unacceptable air exchange in cubic feet per minute (CFM). Later indoor air quality studies showed successful remediation of the ventilation problem and compliance with ASHRAE guidelines.

Questionnaire results. The average age of the cases was 52.9 years and 54.4 years for the controls. The three cases were Caucasians. The 15 controls included eleven Caucasians, two Asians, one African American, and one Hispanic. The three cases did not live in the same residential area, and therefore did not share a common residential water supply or other residential environmental factors. The average Body Mass Index (BMI) (BMI was calculated with the following formula: [Weight in pounds $\div$ Height in inches] $\times 703=$ BMI $\mathrm{kg} / \mathrm{m}^{2}$ ) of the cases was $32.3 \mathrm{~kg} / \mathrm{m}^{2}$ and for the controls $29.3 \mathrm{~kg} / \mathrm{m}^{2}$. The one case that had children gave birth at age 19 and seven of the 15 controls (46.7\%) had their first full term pregnancy at age 20 or younger. The case did not breastfeed any of her children and the controls breastfed an average of 3.7 months. Two cases $(66.7 \%)$ and 12 controls $(80 \%)$ were post-menopausal. Oral contraceptives were used an average of 8.0 years for the cases and 4.9 years for controls. Hormone replacement therapy was used an average of 6.7 years for cases (who took HRT until diagnosis) and 2.1 years for controls. Two of three cases $(66.7 \%)$ had a positive family history of breast cancer (the mother of the third case was adopted and no data were available on the maternal side). Only one of the fifteen controls $(6.7 \%)$ had a family history of breast cancer. The mother and sister of one case were diagnosed with breast cancer. The second case had two aunts and a cousin diagnosed with breast cancer at a young age and the aunts both also developed ovarian cancer. The control had two first-degree relatives diagnosed with breast cancer, mother and sister respectively. Cigarettes were smoked 11 years for one case and an average of 27.6 years for 5 controls. Pesticides and herbicides were used an average of 27.5 years for 2 cases and 10.4 years for 5 controls.

Pathology. All three cases exhibited a histopathological phenotype of florid lymphovascular invasion (tumor emboli 
within lymphovascular spaces). Lymphovascular emboli within dermal lymphatics were especially prominent (Fig. 2C). These emboli appeared as compact clusters of tumor cells in the central portions of the vascular lumens with apparent retraction away from the vascular endothelial cells (Fig. 2C).

E-cadherin membrane immunoreactivity was present in these lymphovascular emboli in all three cases (Fig. 2A). The lymphovascular tumor emboli in all three cases exhibited strong MUC-1 immunoreactivity but weak to absent sialylLewis X/A immunoreactivity (Fig. 2B). Adjacent normal ducts and acini showed markedly decreased E-cadherin and MUC-1 immunoreactivity but increased sialyl-Lewis X/A immunoreactivity (Fig. 2B).

\section{Discussion}

The occurrence of three cases of IBC in an office setting in less than a year has not, to the best of our knowledge, been previously reported. IBC was documented by both clinical and pathologic evaluation with all three cases having invasion of the dermal lymphatics and immunopathologic features of IBC. IBC is characterized by tumor emboli within lymphovascular spaces termed lymphovascular invasion.

Cancer clusters are a notoriously difficult subject to interpret (15). The long latent period between initiation and clinical presentation for most cancers means a cluster is likely to be of biological significance if it occurs in an occupational situation (16). Other biological links can be noted when relatively rare tumors and/or malignancies with a very rapid doubling time appear. IBC is relatively rare and has a rapid doubling time. Many clusters go unresolved perhaps because they are statistical anomalies rather than biological. A cluster study, however can lead to the development of hypotheses that can be tested in more systematic studies, such as case control studies.

A possible link between the environment and development of IBC is documented in a study of 581 Tunisian women with aggressive breast cancer, $45 \%$ meeting the AJCC criteria for IBC, where the ratio of IBC to non-IBC breast cancer was markedly higher in the rural population than the urban population (6). Other findings indicate that there is a possible association between hormonal stimulation and the development of IBC, but the authors were only able to collect information on the time period for the first births in a small subset of the population (6). Chang et al showed that obesity, which is associated with increased estrogen production, may serve as a contributor to IBC development (17). Another potential factor includes insulin-like growth factor-1 because it is involved in carcinogenesis and associated with obesity. It is reasonable to assume that a high BMI sets the stage for the rapid proliferation of malignant cells once a critical point in the carcinogenic process has been reached.

One study has shown that exposure to organochlorines is associated with more aggressive tumor behavior (7); several organochlorines have been shown to elicit responses that may mimic or antagonize the effects of endogenous sex hormones (7) which could possibly influence the growth or aggressiveness of breast cancer. This is important for IBC, because it is a cancer that presents itself and grows rapidly.

Concern has arisen in the scientific community regarding the potentially adverse health effect that can develop from
MRI exposure. The positioning of the Eden Valley office above the East Bay MRI Imaging Center provided an opportunity for long term employee exposure due to possible radiation leakage. Studies have attempted to show a correlation between electromagnetic field exposure and breast cancer, but the current literature is mixed and inconclusive (18-24). No surveys of the mammography center were performed during the operation of old equipment, which was replaced in 1999. The lack of measurements with the original mammography machine prevents estimation of the true exposures experienced by the employees.

Additionally, for workers who handle CCP, the most common exposures are formaldehyde and kerosene or its components (25). Regarding the risk of cancer, formaldehyde has been noted to be etiologically related to sino-nasal carcinoma (26). While elevations in risks have been noted in other cancer types also, no linkage has been identified in breast cancer.

Studies on OC use and breast cancer prognosis have yielded contradictory results. A number of studies showed no association with OC use on prognosis (27-31), a number found that OC users had smaller tumors and were less advanced clinically $(32,33)$, and a number found that OC users had a worse prognosis (9,34-37). It is difficult to compare the studies because many of the studies have not investigated dose and composition and these have changed over time (38).

Extensive epidemiologic studies have determined that breast cancer is in part hormonally mediated, but the connection between breast cancer and hormonal therapy is not clear. Two of the cases in this cluster were taking hormone replacement therapy at the time of their diagnosis. There is little information on the association of HRT exposure with IBC, but the risk of breast cancer diagnosis increases in women using hormone replacement therapy as the duration of use increases $(39,40)$.

The possibility that agricultural pesticides and herbicides could have an influence not only on breast cancer incidence, but also aggressiveness warrants attention. Organochlorines, although structurally unrelated to estrogen, have the ability to evoke estrogenic responses and thus to interfere with estrogencontrolled pathways (7). These compounds include polychlorinated biphenyls ( $\mathrm{PCBs}$ ), dioxins, triazine herbicides, and pesticides such as dieldrin, dicophane (DDT), and the DDT metabolite dichloroethene (DDE) (41).

Although we were unable to identify a specific etiology for this unusual time-space cluster of IBC, its occurrence lends support to the hypothesis that environmental factors may be important contributors to IBC etiology. Studies of clusters can lead to knowledge regarding etiologic agents. Tumor promotion appears to be an important factor in this cluster and further studies may help in understanding IBC. The cases' previous exposures to pesticides/herbicides, oral contraceptives and hormone replacement therapy, pregnancy history and family history of breast cancer are strong and when coupled with the documented environmental exposures in the work place may have led to the accelerated development of aggressive IBC breast tumors.

In conclusion, the data indicate that oral contraceptives and hormone replacement therapy use, obesity, and exposure to pesticides and herbicides, may have contributed to this 
unusual cluster of IBC cases. It is not possible to explain how the combinations of environmental factors affected these 3 women. However, each woman had strong exposures to agents and/or factors that may be associated with tumor progression. The compromised conditions in their work space over a long duration may well have contributed to the aggressive developments of their breast cancer.

It is important to note that while most cluster studies do not lead to the determination of the cause of the clusters, we undertook this study in order to develop hypotheses for IBC risk factors. Even when there is a potential environment, condition, or combination of conditions with a biologically plausible hypothesis of how it might contribute to cancer, trying to trace cancer cases to a specific cause poses unique challenges. Unlike outbreaks of infectious diseases, which can be linked to some recent exposure, a cluster of cancer cases might have its roots in an exposure that occurred 10 to 20 years earlier (42); conversely, however, IBC is a rapidly growing tumor like Burkitt's lymphoma (BL), which has a doubling time of $24 \mathrm{~h}$, and a time-space clustering is more likely to indicate a proximate cause. The objective was to use this observation to look for etiologic clues in IBC and highlight areas where additional documentation and research are necessary. The findings from this apparent cluster, although inconclusive, should be tested out on larger case-control studies under development at large institutions.

\section{Acknowledgements}

We thank Ms. Barbara Severini who was instrumental in facilitating collection of environmental data and recruitment of controls. We also would like to thank all of the study participants and funding agencies for contributing to the work of this study. The opinions in this manuscript are those of the authors and do not necessarily represent the opinions and/or policies of the U.S. Environmental Protection Agency. Supported in part by Grant no. DAMD 17-01-1-0244 with the Department of Defense and the Inflammatory Breast Cancer Research Foundation.

\section{References}

1. Hance KW, Anderson WF, Devesa SS, Young HA and Levine PH: Trends in inflammatory breast carcinoma incidence and survival: the surveillance, epidemiology, and end results program at the National Cancer Institute. J Natl Cancer Inst 97: 966-975, 2005.

2. Levine PH, Steinhorn SC, Ries LG and Aron JL: Inflammatory breast cancer: the experience of the surveillance, epidemiology, and end results (SEER) program. J Natl Cancer Inst 74: 291-297, 1985.

3. Chang S, Parker SL, Pham T, Buzdar AU and Hursting SD: Inflammatory breast carcinoma incidence and survival: the surveillance, epidemiology, and end results program of the National Cancer Institute, 1975-1992. Cancer 82: 2366-2372, 1998.

4. Wingo PA, Jamison PM, Young JL and Gargiullo P: Populationbased statistics for women diagnosed with inflammatory breast cancer (United States). Cancer Causes Control 15: 321-328, 2004.

5. Williams CKO, Olopade OI and Falkson CI: Breast cancer in women of African descent. Springer, Dordrecht pp91-188, 2006.

6. Mourali N, Muenz LR, Tabbane F, Belhassen S, Bahi J and Levine PH: Epidemiologic features of rapidly progressing breast cancer in Tunisia. Cancer 46: 2741-2746, 1980.
7. Demers A, Ayotte P, Brisson J, Dodin S, Robert J and Dewailly E: Risk and aggressiveness of breast cancer in relation to plasma organochlorine concentrations. Cancer Epidemiol Biomarkers Prev 9: 161-166, 2000.

8. Chie WC, Hsieh C, Newcomb PA, et al: Age at any full-term pregnancy and breast cancer risk. Am J Epidemiol 151: 715-722, 2000.

9. Veneroso C, Siegel R and Levine PH: Early age at first childbirth associated with advanced tumor grade in breast cancer. Cancer Detect Prev 32: 215-223, 2008.

10. Alpaugh ML, Tomlinson JS, Shao ZM and Barsky SH: A novel human xenograft model of inflammatory breast cancer. Cancer Res 59: 5079-5084, 1999.

11. Tomlinson JS, Alpaugh ML and Barsky SH: An intact overexpressed E-cadherin/alpha, beta-catenin axis characterizes the lymphovascular emboli of inflammatory breast carcinoma. Cancer Res 61: 5231-5241, 2001.

12. Alpaugh ML, Tomlinson JS, Kasraeian S and Barsky SH: Cooperative role of E-cadherin and sialyl-Lewis X/A-deficient MUC1 in the passive dissemination of tumor emboli in inflammatory breast carcinoma. Oncogene 21: 3631-3643, 2002.

13. Alpaugh ML, Tomlinson JS, Ye Y and Barsky SH: Relationship of sialyl-Lewis(x/a) underexpression and E-cadherin overexpression in the lymphovascular embolus of inflammatory breast carcinoma. Am J Pathol 161: 619-628, 2002.

14. American Society of Heating and Refrigerating, and Air Conditioning Engineers (ASHRAE). Ventilation for acceptable indoor air quality. Standard 62, 1999. http://www .ashrae.org.

15. Rothenberg RB, Steinberg KK and Thacker SB: The public health importance of clusters: a note from the Centers for Disease Control. Am J Epidemiol 132: S3-S5, 1990.

16. Creech JL Jr and Johnson MN: Angiosarcoma of liver in the manufacture of polyvinyl chloride. J Occup Med 16: 150-151, 1974.

17. Chang S, Buzdar AU and Hursting SD: Inflammatory breast cancer and body mass index. J Clin Oncol 16: 3731-3735, 1998.

18. McElroy JA, Egan KM, Titus-Ernstoff L, et al: Occupational exposure to electromagnetic field and breast cancer risk in a large, population-based, case-control study in the United States. J Occup Environ Med/American College of Occupational and Environmental Medicine 49: 266-274, 2007.

19. Floderus B, Stenlund C and Persson T: Occupational magnetic field exposure and site-specific cancer incidence: a Swedish cohort study. Cancer Causes Control 10: 323-332, 1999.

20. Kliukiene J, Tynes T, Martinsen JI, Blaasaas KG and Andersen A: Incidence of breast cancer in a Norwegian cohort of women with potential workplace exposure to $50 \mathrm{~Hz}$ magnetic fields. Am J Ind Med 36: 147-154, 1999.

21. Kliukiene J, Tynes T and Andersen A: Follow-up of radio and telegraph operators with exposure to electromagnetic fields and risk of breast cancer. Eur J Cancer Prev 12: 301-307, 2003.

22. Labreche F, Goldberg MS, Valois MF, et al: Occupational exposures to extremely low frequency magnetic fields and postmenopausal breast cancer. Am J Ind Med 44: 643-652, 2003.

23. Kliukiene J, Tynes T and Andersen A: Residential and occupational exposures to $50-\mathrm{Hz}$ magnetic fields and breast cancer in women: a population-based study. Am J Epidemiol 159: 852-861, 2004.

24. Forssen UM, Rutqvist LE, Ahlbom A and Feychting M: Occupational magnetic fields and female breast cancer: a casecontrol study using Swedish population registers and new exposure data. Am J Epidemiol 161: 250-259, 2005

25. NIOSH Hazard review carbonless copy paper. DHHS (NIOSH) Publication No. 2001-107, 2000. http://www.cdc.gov/niosh/ pdfs/01-107.pdf.

26. Hansen J and Olsen JH: Formaldehyde and cancer morbidity among male employees in Denmark. Cancer Causes Control 6: 354-360, 1995.

27. Rosner D and Lane WW: Oral contraceptive use has no adverse effect on the prognosis of breast cancer. Cancer 57: 591-596, 1986.

28. Greenberg ER, Vessey MP, McPherson K, Doll R and Yeates D: Body size and survival in premenopausal breast cancer. Br J Cancer 51: 691-697, 1985.

29. Mohle-Boetani JC, Grosser S, Whittemore AS, Malec M, Kampert JB and Paffenbarger RS Jr: Body size, reproductive factors, and breast cancer survival. Prev Med 17: 634-642, 1988. 
30. Rosner D, Lane WW and Perez Brett R: Influence of oral contraceptives on the prognosis of breast cancer in young women. Cancer 55: 1556-1562, 1985.

31. Rosner DH, Joy JV and Lane WW: Oral contraceptives and prognosis of breast cancer in women aged 35 to 50. J Surg Oncol 30: 52-59, 1985.

32. Sauerbrei W, Blettner M, Schmoor C, Bojar H and Schumacher M: The effect of oral contraceptive use on the prognosis of node positive breast cancer patients. German Breast Cancer Study Group. Eur J Cancer 34: 1348-1351, 1998

33. Breast cancer and hormonal contraceptives: collaborative reanalysis of individual data on 53297 women with breast cancer and 100239 women without breast cancer from 54 epidemiological studies. Collaborative Group on Hormonal Factors in Breast Cancer. Lancet 347: 1713-1727, 1996.

34. Schonborn I, Nischan P and Ebeling K: Oral contraceptive use and the prognosis of breast cancer. Breast Cancer Res Treat 30: 283-292, 1994

35. Brinton LA, Daling JR, Liff JM, et al: Oral contraceptives and breast cancer risk among younger women. J Natl Cancer Inst 87: 827-835, 1995

36. Kay CR and Hannaford PC: Breast cancer and the pill-a further report from the Royal College of General Practitioners' oral contraception study. Br J Cancer 58: 675-680, 1988.
37. Olsson H, Borg A, Ferno M, Moller TR and Ranstam J: Early oral contraceptive use and premenopausal breast cancer - a review of studies performed in southern Sweden. Cancer Detect Prev 15: 265-271, 1991.

38. Gerstman BB, Gross TP, Kennedy DL, Bennett RC, Tomita DK and Stadel BV: Trends in the content and use of oral contraceptives in the United States, 1964-88. Am J Public Health 81: 90-96, 1991.

39. Davidson NE: Is hormone replacement therapy a risk? Sci Am 275: 101,1996

40. Johnson-Thompson MC and Guthrie J: Ongoing research to identify environmental risk factors in breast carcinoma. Cancer 88: 1224-1229, 2000.

41. Kettles MK, Browning SR, Prince TS and Horstman SW: Triazine herbicide exposure and breast cancer incidence: an ecologic study of Kentucky counties. Environ Health Perspect 105: 1222-1227, 1997.

42. Kase LM: Why community cancer clusters are often ignored. Sci Am 275: 85-86, 1996. 